\title{
An Investigation of Abstract and Discussion Sections in Master's Dissertations
}

\author{
Muhammad Afzaal ${ }^{1}$, Kanglong Liu ${ }^{2}$, Baoqin $\mathrm{Wu}^{3}$, Rahiba Sayyida ${ }^{4} \& \mathrm{Swaleha} \mathrm{Bano} \mathrm{Naqvi}^{5}$ \\ ${ }^{1}$ Institute of Corpus Studies and Applications, Shanghai International Studies University, China \\ ${ }^{2}$ The Hong Kong Polytechnic University, Hong Kong \\ ${ }^{3}$ East China Normal University, China \\ ${ }^{4}$ NCBA, Multan, Pakistan \\ ${ }^{5}$ Foundation University Islamabad (Rawalpindi Campus), Pakistan \\ Correspondence: Muhammad Afzaal, Institute of Corpus Studies and Applications, Shanghai International \\ Studies University, China. E-mail: muhammad.afzaal1185@gmail.com
}

Received: September 15, 2019 Accepted: October 28, 2019 Online Published: December 28, 2019

doi:10.5539/ijel.v10n1p220ＵRL: https://doi.org/10.5539/ijel.v10n1p220

\begin{abstract}
This study analyzes the differences between the academic writing of undergraduate students belonging to two Pakistani universities, one located in an urban setting and the other in a rural locale, in an attempt not only to identify why these differences may arise but also how such learners may be encouraged to more readily adopt academic writing techniques in their theses. Data comprises the abstract and discussion sections of undergraduate students' dissertations. The study uses Swales' CARS model to analyze the academic writing proficiency demonstrated in the selected data. The study finds that the occurrences of a particular move were more frequent in the dissertations of the rural area students. In contrast, the instantiation of hedges was significant in the dissertations of learners from the urban area university. These observed differences confirm the perception that in terms of academic writing "quality", the universities in rural settings in Pakistan are not sufficiently competitive with peer institutions in urban settings. The study further reveals that dissertations from rural setting universities reflect poor use of rhetorical moves associated with good academic writing, while in line with Swales' CARS model, students from the urban university show significant linear patterns and accuracy in their academic writing.
\end{abstract}

Keywords: ESP, hedges, CARS model, academic dissertations, moves structure

\section{Introduction}

Academic writing is distinctive from non-academic writing. In addition to a precise and accurate use of language and well-planned and organized writing, academic writing is thesis-driven, adheres to academic conventions and demonstrates complexity and higher order thinking (Larabee, 2009). In the course of their degrees, scholars are expected to write research papers, academic dissertations and research proposals which reflect an understanding of these academic writing features. In addition to being an official language in Pakistan, English is also the medium of instruction, communication and assessment in Pakistani tertiary settings. This means that Pakistani students who have learnt English as a Second Language (ESL) to varying levels of competence can find it a struggle to successfully adopt academic writing features in their dissertations. There is a major difference in the use of academic language by native and non-native writers. The lexical choices, grammatical usage and argumentation of native writers demonstrate proficient use of academic writing conventions, whereas such competence is not equally evident in the writing of non-natives. As a result, the dissertations and research articles written by non-native scholars are often unable to match those authored by native writers in terms of academic writing quality.

This study examines the abstract and discussion sections within the dissertations authored by Master's level Pakistani students to gauge the extent to which academic writing moves identified in the Creating a Research Space (CARS) model proposed by Swales (1990) are in evidence. A special feature of academic writing is discourse organization. Genre analysis shows that language has distinctive functions in which certain language conventions entail specific purposes, and that these can vary according to the primary basis of a particular text. It 
is this type of discourse analysis that has garnered great attention in applied linguistics. However, most applications for academic writing practices extend beyond the conventions of genre and extend towards specific writing functions and practices.

Nasseri and Nematollahi (2014) performed a Move-step analysis using Santos' model on the introduction section of Iranian theses and found a discrepancy in the recurrence of literary functions employed in the academic writing of two groups of native and non-native speakers. This reasoning was anticipated by Mohan and Lo (1985) who suggested that such discrepancy was likely to be due to developmental factors and variances in curriculum/teaching style rather than due to transference variance caused by different style between the two groups. Thus, the idea that developmental transfer is likely to apply to variations between the occurrence and the patterns of linguistic functions in academic writing demonstrated by two different learner groups forms the central point of and justification for this research.

Another specific feature of academic writing, as highlighted by Hyland (2000), is hedging, which is an important tool for writers to dispute and construct claims by dictating the reader's attitude and perception towards said claims. They are considered an important part of academic discourse due to the interpersonal nature of academic writing where the writer must anticipate and account for any contrary views that the target audience, or the reader, may have. As L2 learners find it particularly challenging to deploy hedges, this also comprises a key focus in our research. Although Kaplan (1972) attributed this problem in the academic writing of non-native writers to cultural differences, second language acquisition has shown that such challenges can also be linked back to the grammatical and syntactic structure of their writing.

It has been argued by MacDonald (1994) that academic writing must be approached as a practice that involves a formulation of thought and rhetoric rather than as a practice. Such a practice is one now believed to evidence a much higher discrepancy between formulated thought and already existing ideas. Thus, an examination of specific literary features involved in the construction and expression of observation becomes imperative as researchers are becoming increasingly interested in the examination of the language of their own texts. Further, even though certain variations may be observed in cross-disciplinary fields, writers still display variation with respect to literary practices as discernible in the interpretation, construction and communication of discourse. Thus academic prose has evolved as a "vehicle for constructing claims" which is contingent upon the effective formulation of thought in academic writing. MacDonald also states that not only is there a lack of development of the tools for examining these nuanced literary features but also that academic features within texts have not been extensively examined.

In their article, Mohan and Lo (1985) discussed the variance in features of academic writing between groups of native and non-native English speakers. While acknowledging that some of the problems faced by second language learners writing academic English are attributable to syntax related issues pertaining to vocabulary and grammar, discourse organization in particular is a feature of academic writing that warrants greater study. This discussion of discourse organization extends to the variances across academic writing in cultural settings and attempts to ascertain whether the practices of discourse organization, structures of academic knowledge and development of the ability to produce academic discourse are universal or arise from cultural boundaries. These variances and their occurrence as cultural or universal phenomenon can be more accurately described as occurring due to development factors or transferal factors. To put it into perspective, Kaplan (1972) argues that the nature of exposition variances across native and non-native speakers may be explained by languages having a distinct prose, thus suggesting that this provides a justification for transferal factors being more significant than development factors. However, these claims were suggested as being non-satisfactory by Mohan et al. due to Kaplan's examination of prose that is considered redundant in modern contexts and thus extends toward academic writing. Further, due to the similarities in sentence and statement structure, it can be considered equally likely that positive transfer may also play a role. In contrast, Mohan's impression of the results of 1400 surveys administered to teachers in British Columbia by Evanechko, Armstrong, Dey, Johnson, Quorn, and Smith (1976) was corroborated with interview data from ten teachers in Hong Kong and led to the identification of recurring differences in the developmental styles taught in classrooms. Consequently, the author suggests that the differences in discourse organization has little do with varying prose between languages but instead is a result of developmental discrepancies between the different styles of the English and Chinese teaching programs.

\section{Swales' Model of Rhetorical Moves in Research Articles (CARS)}

It is important to define genre in the context of the linguistic approach which also extends its role toward English for Specific Purposes or ESP (Swales, 1990). This approach to genre within a specific discourse community serves as the basis for the Create a Research Space (CARS) model wherein writers structure discourse in the 
form of specific "Moves" expressed by "Steps". However, given the dynamic nature of most discourse, different variations of the CARS model may be used in order to more accurately ascertain specific communicative discrepancies between large volumes of text (Brett, 1994). The occurrence of these moves as well as their patterns may possibly serve to explain specifically cultural approaches toward academic writing which factor in other features such as grammatical patterns (Nasseri \& Nematollahi, 2014). Moreover, the importance of "hedges" as a style of communicative option also establishes its centrality through its frequent occurrence in all discourse communities, even ones which are less discursive in nature and more reliant on quantitative data obtained through repeated experimental methods in comparison with those that rely on statistical models to derive meaningful interpretations of observations or rely on purely speculative claims (Hyland, 2000). These occurrences may or may not vary across learners but remain an important tool in the analysis of the specific features of academic writing.

In order to analyze whether academic work is of great worth and patterned in an academic style, Swales, after examining the structure of abstracts and discussions produced by ESL writer, proposed a sequence of rhetorical moves through which writers can create a connection of ideas, coherence, establish a link of ideas in order to. The following key rhetorical moves were proposed by Swales (1990):

\section{Move 1: Establishing a territory}

Step 1: Claiming centrality and/or

Step 2: Making topic generalization(s) and/or

Step 3: Reviewing items of previous research

\section{Move 2: Establishing a niche}

Step 1A: Counter-claiming or

Step 1B: Indicating a gap

Step 1C: Question-raising

Step 1D: Continuing a tradition

\section{Move 3: Occupying the niche}

Step 1A: Outlining purposes

Step 1B: Announcing present research

Step 2: Announcing principal findings

Step 3: Indicating Research Article structure

Another approach to examining academic writing offered by Chen and Baker (2010) focuses on the quantification of recurring phrases dubbed as lexical bundles. By virtue of its nature, the said formulaic linguistic expression is believed to have "processing advantage over creatively generated language". For the purpose of examining the recurrence of lexical bundles between varying language proficiency classes, a corpus of three groups was examined and used as a representation of native language expert writing, native peer writing and learner writing. An analysis through wordsmith 4.0 and exclusion of discipline-exclusive phrases showed that while some recurrences such as over generalization and the use of cautious language were more prevalent in the non-native writer corpus, there were many similarities between lexical bundles across all three groups as a whole The only significantly observed difference was between the usage of noun-preposition or "NP" and verb composition of "VP" phrases whereby native speakers demonstrated a higher tendency towards the latter which may be interpreted by some readers as a more "immature" writing style. Chen and Baker (2010) concluded that being native speakers of English did not significantly impact writers' ability to construct discourse around these lexical bundles. The authors noted that this would appear to suggest that the writer's familiarity with the material itself played a more significant role in the usage of recurrent phrases. Biber, Conrad, and Cortes (2003) observed a significant variance in the occurrence of lexical bundles in the discourse of writers of two distinct expertise levels. This variance in usage was also observed as an inter-disciplinary phenomenon by Hyland (2008) .

According to Hyland (2005), academic interaction is based on the communicative options employed by the writer and thus it is important to segregate these interactions into stances and engagements. Stances pertain to the way writers make claims which ranges from the writers asserting their authority as subject experts to distancing themselves from their claims by acknowledging the said claims as being speculative in nature. According to Hyland, stances and engagements can be further separated into distinct markers, given that engagements are much more dynamic in nature and advocate a position of mutuality between the writer and the reader. However 
due to the contextual nature of discourse and overlap of function where writers provide detailed justifications and elaboration for their claims, it is important to note that this distinction is not always distinctly apparent.

Besides this, Hyland (2000) has also commented on the rhetorical nature of academic writing in which a considerable number of applied linguistic functions are used to transform the researcher's findings into knowledge within the discourse community. Hyland thus identified and classified hedges into distinct functions each with their own unique critical role by anticipating any potential opposition to the claims of the writer. These hedges are primarily used to construct statements that meet adequacy conditions and to satisfy acceptability conditions. However, due to the poly-pragmatic nature of hedges, there is an overlap between intended function and thus some subjectivity in making distinction between the functions. One of these distinctions is content-oriented hedges that serve as a way to link propositional statements and the discourse community's perception of established scientific knowledge. Content oriented hedges involve the writer's need for expressing claims and propositions which are as close as possible to already established discourse (accuracy-oriented hedges) and for anticipating contrary discourse where it occurs (writer-oriented hedges). This addresses the following research questions: What are the organizational traits in dissertations at the master's level in English? And what are the linguistic features in master level dissertations?

\section{Method}

The study identifies the organizational traits in the perspective of academic proficiency of dissertations written by Pakistani students who are completing their master's degrees in the English language. Selected English dissertations are analyzed in the light of Swales' CARS model, with the major focus of the analysis comprising the move structure and patterns in the proficiency in their writing. The study selected six dissertations from students at two campuses of universities situated in urban and rural settings in Pakistan. Three dissertations were obtained from Foundation University Rawalpindi situated in Rawalpindi city which is part of the greater Rawalpindi-Islamabad metropolitan area and is the 3rd largest area in Pakistan in terms of total population at 7.7 million (Provisional summary results of 6th population and housing census-2017, 2017). The other three dissertations were obtained from Grafton College situated in Jhelum which is a rural town in Pakistan.

\section{Results and Discussions}

Analysis of the data shows a significant difference in the perceived importance of the methodology and coverage accorded to it in the abstract sections of the theses. Conversely, many of the trends displayed a similar occurrence across both groups. However, these trends are still peculiar in nature and may be explained by factors shared across both groups instead of the variables. On the other hand, upon examination of the use and employment of hedges, a significant difference was consistently observed between the dissertations from the two groups. It was found that the group correlating to the urban setting consistently displayed the usage of hedges when making knowledge claims whereas the group correlating to the rural learners gathering did not use hedges - often stating claims outright without any sort of modality or space for the readers to make refutations. This may be attributed to the developmental factors across the learner groups wherein the course program demands and instruction were insufficient to orient students to established practices for effective academic writing. Similarly, our analysis of moves showed that writers from both groups tended to exclude writer oriented hedges completely. Once again, this difference may be better explained through examination of the underlying similarities between two groups instead of variances. Table 1 shows the theses examined for the word counts expressed in the introduction and the discussion of rural area campus tagged as A:

Table 1. Length of abstract of the theses of Grafton College NUML Campus

\begin{tabular}{ll}
\hline Sample number & Length of Abstract \\
\hline A1 & 227 \\
A2 & 127 \\
A3 & 124 \\
Average & 159.3 \\
\hline
\end{tabular}

Similarly, the word count and the length of dissertations of urban university as tagged as B are given in Table 2 . 
Table 2. Length of abstract of the theses of Foundation University Rawalpindi Campus

\begin{tabular}{ll}
\hline Sample number & Length of Abstract \\
\hline B1 & 174 \\
B2 & 216 \\
B3 & 242 \\
Average & 210.6 \\
\hline
\end{tabular}

On average, it is observed that the word count of the abstracts belonging to group B have 51.3 more words on average or $32.2 \%$ more words on average. This difference may be accounted for by the tendency of group A to explain their methodology and methods more concisely and it is discussed further in the next section.

\subsection{Move Structure}

The theses of the two distinct learner groups were then examined for the occurrence of moves in line with the CARS model. These theses were classified as thesis from group A or from group B.. Moves that occurred repeatedly or were cyclical in nature were not noted. These occurrences were recorded as below:

\section{Move 1: Establishing a territory}

In the examined corpus, 2 abstracts from group A and 4 from group B displayed this move, for a total of 4 out of 6 abstracts. The move is further divided into 2 distinct sub-moves with 1 sub-move having 3 distinct elements:

\section{Sub-Move 1A: Claiming centrality and/or}

This Sub-Move is realized by a statement of current knowledge which may involve generalizations established in the field, stating a growing concern in the field involved or the state of currently ongoing practices and conventions in the field.

Sub-Move 1A was observed in the following thesis as below:

Sample A1: "With the growing importance and need of English language in the global context, efforts are being made in developing context to improve quality of teaching English with the assumption that teaching of English facilitates the acquisition of English Language (Ali Nawab, 2012). What are the strategies of English language teachers in Pakistan at primary level and does the way they teach effectively and facilitate the language acquisition?"

In thesis sample A1, Sub-Move $1 \mathrm{~A}$ is observed as the author establishes or states an emerging concern in the field with the opening phrase "With the growing importance...".

Sample A3: "Learner does generally want to be proficient in actively using the foreign language. However, they come in class with motivations, attitude and learning histories that are said to be factors that influences their language learning process."

Sub-Move $1 \mathrm{~A}$ is observed in thesis sample A3 wherein the author establishes centrality of the subject by stating its significance to practitioners in the opening phrase "Learner does generally want to be proficient..."

Sample B1: "Children learn or develop language from the social interaction around them and the type of people they interact with. They spend most of the time at home with their parents and the interaction patterns that occur in the conversation influence by the way their children learn language. Parents might encounter numerous problem developing language in the children."

Sub-Move 1A is observed in thesis sample B1 in which the writer states the background information by mentioning the contextual background of the subject of interest "Children learn or develop language from the social interaction around them and the type of people they interact with" and links it with an emerging problem "Parents might encounter numerous problem developing language in the children".

\section{Sub Move: Making topic generalization(s) and/or}

Sub-Move 1B was not observed in any of the abstracts examined and there was a lack of effort to establish connection of topic to previous researches.

\section{Sub-Move 1C: Reviewing items of previous research}

Sub-Move 1C was not observed in any of the abstracts examined and no attempt was made by the writers to present the research as an extension or continuation of recently performed works.

\section{Move 2: Stablishing a niche}

Move 2 occurred in 2 out of 3 abstracts for group A and all 3 abstracts in group B for a total of 5 out of 6 
occurrences. Move 2 was expressed in terms of its sub-Move functions.

\section{Sub-Move 1A: Counter-claiming or}

Sub-Move 1A was observed in 2 out of 3 theses for group A and all 3 abstracts in group B. It was observed as follows and relevant sections are underlined:

Sample A1: "The current study explores this question in the context of District Jhelum. The researcher visited 30 schools randomly and consulted English teachers interviewing them and observing the teaching and learning processes. The study shows that in the context of District Jhelum, the teaching of English is not different from teaching of other subjects such as Social studies, Urdu and Islamic studies. GM is the dominant method to teach English and learners hardly get any opportunity to practice language skills in the classrooms."

Sample A2: "A study was conducted to research the effects of music and songs as an aid to learn English as a second language. The purpose of the study was to suggest alternate methods to the conservative teaching style for teaching new languages."

Sample B1: "The aim of the study was to examine parents' interactions and reasons for unsuccessful communication when teaching English as a second language to your young learners."

Sample B2: "The study is an attempt to discuss in what ways the TV news reports choose to embellish the content and what visuals or aural addictions are made to the news reports to make them more appealing to the viewers. The introduction to the study talks about the media in Pakistan and their growth. It also introduces the reader to the notion of embellishments." Sample B3: "Therefore, study in question, investigates this relationship further in consonance with four components of Post-Traumatic Stress Disorder, thereby analyzing how combat related Post Traumatic Stress Disorder is associated with work performance of veteran employees of Pakistan Army (Sajjad \& Arshad, 2015).”

Table 3. Specific choices of language observed for expressing Move 2, Sub-Move 1A

\begin{tabular}{llll}
\hline & Dialectic item & Inquiry type/genre & Reporting verb \\
\hline Group A & The (2) & Study (2) & To suggest (1) \\
& & & Explores (1) \\
Group B & The (3) & Study (3) & To discuss (1) \\
& & & Investigates (1) \\
& & & To investigate (1) \\
\hline
\end{tabular}

With reference to Table 3, dialectic items in group A refer to the reference made to the "item" which the inquiry type/genre further expands on. This is then further given contextual importance through the reporting verb. The reporting verb in this case refers to the "action" performed by the study in terms of its primary intent. In the table, within group A, no significant variation was found between in the reporting verbs used in the students' writing and the choice of words for referring to the dialectic items and the inquiry type remained the same.

\section{Sub-Move 1B: Indicating a gap}

In the examined corpus, only one of the three abstracts in group A stated purpose, and similarly only one of the three abstracts in group B stated purpose. These were observed as follows:

Sample A2: "The purpose of the study..."

Sample B1: "The aim of the study..."

\section{Sub-Move 2: Question-raising}

None of the abstracts examined displayed this particular sub-Move.

\section{Sub-Move 3: Continuing a tradition}

None of the academic dissertations examined displayed this particular sub-Move.

\section{Move 3: Describing the methodology}

Move 3 was observed to occur in all three of the abstracts in group A and two of the three abstracts ingroup B. It was observed and noted as follows: 
Sample A1: "The researcher visited 30 schools randomly and consulted English teachers interviewing them and observing the teaching and learning processes." Sample A2: "Through questionnaires and surveys, it was attempted to determine if music as teaching tool had any positive effect on acquiring a new language."

Sample A3: "This research was conducted in ESL classes. The study participations were 15 students. Data was collected by using a mixed-methods approach with surveys and follow-ups interviews, and was analyzed by using descriptive statistics and content analysis."

Sample B1: "It further analyzed the patterns which appeared to support ESL learning with regard to the IRF model proposed by Sinclair and Coulthard in 1975. This study presented analysis of spoken data taken from the real-life conversation of parent and child when teaching ESL to young learners. The main source of data was comprised transcripts of parent-child conversations."

Sample B2: "The second chapter offers a look at the methodology of the study including the collection of the data, their analysis and the research question the study aims to answer."

In 4 out of 5 examined verb phrases, it was observed that they occurred in the past tense as opposed to present or present participle.

Table 4. Verb tense used for expression of Move 3 in the 6 observed abstracts

\begin{tabular}{ll}
\hline Past participle & Progressive tense \\
\hline Visited & Offers \\
Attempted & Attempts \\
Conducted & Held \\
Analyzed & Analysed \\
\hline
\end{tabular}

It was observed in Table 4 that past participle was used as an expression for move 3 almost exclusively across both these groups, which may indicate a lack of confidence within students as a whole to present their study as being relevant in the current landscape of discourse.

\section{Move 3: Occupying the niche}

\section{Sub Move 1A: Outlining purposes}

In the observed corpus, all six abstracts ( 3 from group A and 3 from group B) displayed this move. It was observed and noted as follows:

Sample A1: "The study shows that in the context of District Jhelum, the teaching of English is not different from teaching of other subjects such as Social studies, Urdu and Islamic studies. GM is the dominant method to teach English and learners hardly get any opportunity to practice language skills in the classrooms"

Sample A2: "Quite substantial evidence was found in favor of using Music as a teaching tool."

Sample A3: "Results have shown that learner's beliefs and their language background have influence on their perception of learning and teaching methods. In terms of enjoyment of such parties there was an apparent inclination towards interactive and communicative approaches rather than traditional, non-communicative ones, whereas, no distinct style favored in regard to effectiveness."

Sample B1: "The study found out that IRF pattern in parent-child conversation doesn't always exist. However, some unique or non-IRF pattern that occurred in parent-child conversation was the main reason of unsuccessful communication."

Sample B2: "The next chapter talks about the findings of the study and shows which embellishments in the reception of the newspaper reports."

Sample B3: "The resulted shows that only 13\% expressed severed symptoms. Almost half (47\%) expressed moderate symptoms. More than half expressed mild symptoms. From overall sample space, $58 \%$ expressed no symptoms for PTSD compared to $41 \%$ that did."

These occurrences were further broken down as shown in Table 5: 
Table 5. Specific reporting verbs used to express Move 4 by usage

\begin{tabular}{lll}
\hline & Genre & Reporting verb \\
\hline Group A & Study (1) & Showed (1) \\
& Results (1) & Shows (1) \\
Group B & Study (2) & Shows (2) \\
& Results (1) & Found out (1) \\
\hline
\end{tabular}

In Table 5 it was observed that no specific discrepancy between the two groups can be found in the expression of Move 4 and the choice of genre selection and reporting verbs was found to be largely similar throughout.

\section{Sub Move 2 1B: Announcing present research}

Move occurred in two out of the three abstracts from group A and only in 1 out of 3 abstracts from group B. Move 5 can be expressed as a component of two sub-Moves observed as below:

\section{Sub Move 3: Announcing principal findings}

This sub-Move was observed as follows:

Sample A1: "The study suggests that English language teachers should be trained separately focusing teaching English as language unlike other subjects. Studies have also shown the positive effects of word analysis and vocabulary learning strategies on student achievement" (Carlo, August, McLaughlin, Snow, Dressier, Lippmann, Lively, \& White, 2004).

Sample A2: "Hence, this study can help in defining and implementing a dynamic teaching methodology, involving music as a teaching aid, for the learners of English as a second language".

Sample B2: "The conclusion of the study sums up the study and also gives its scope for generalizations."

The underlined phrases conclude the study through the use of suggestive phrases.

\section{Sub Move 4: Indicating Research Article recommendations}

This move was not found to occur in any of the abstracts examined.

\subsection{Discussion}

The Creating a Research Space (CARS) Model was developed by John Swales (1990) based on his analysis of journal articles representing a variety of discipline-based writing practices. His model attempts to explain and describe the organizational pattern of writing found in the introduction portion of scholarly research studies. Following the CARS Model can be a useful approach as it can help writers with: 1) beginning the writing process 2) understanding the way in which an introduction sets the stage for the rest of a paper; and, 3) assessing how the introduction fits within the larger scope of a study. The model assumes that writers follow a general organizational pattern in response to two types of challenges relating to the establishment of a presence within a particular domain of research, namely the competition to create a rhetorical space and the competition to attract readers into that space. The model proposes three actions accompanied by specific steps which reflect the development of an effective introduction in a research paper. These "moves" and steps can be used as a template which writers can use to structure the introductions to their own papers.

It is important to define genre in the context of the linguistics approach which also pertains to English for Specific Purposes or ESP (Swales, 1990). This approach to genre within a specific discourse community serves as the basis of the CARS Model wherein writers express discourse as specific "Moves" expressed by "Steps". However, given the dynamic nature of most discourse, different variations of the CARS model may be used in order to more accurately ascertain specific communicative discrepancies between large volumes of text (Brett, 1994).

The theses of two selected learners were then analyzed for the occurrence of Moves under CARS model. These theses were classified as either thesis from students of Grafton or Foundation University. Thus, corpus analysis showed a total of six moves. Moves which occurred repeatedly or which were intermittent in nature were not viewed. It was observed in the analysis that past participle was used as an expression for move 3 almost exclusively across both these groups, which may indicate a lack of confidence within students as a whole to present their study as being relevant to the current landscape of discourse.

The findings and discussion show that a particular move is found in the dissertation of the learner in the rural setting while the hedges occur more frequently in the dissertations of urban learners. These differences confirm the widely-held view that universities in rural settings in Pakistan cannot compete with those in urban settings 
when it comes to academic writing "quality". The current study shows that there are indeed differences in the academic writing styles of students belonging to different learner groups. Based on the findings of this research, it may be suggested that universities in rural settings could place a stronger emphasis on effective academic writing, incorporate more active usage of these practices across all their programs, and give students appropriate supervision to ensure that these practices become well-integrated into their writing. This would greatly aid these universities in becoming more competitive with more "established" peer institutions in urban settings by helping to produce research that establishes a stronger relationship between reader and researcher and more acceptance within popular journals and publications. The findings of this study imply that further research in this field would be valuable. An interesting area for future research would be to examine learner and teacher perspectives on their understandings of effective academic writing and how these shape students' academic writing practices within rural and urban settings. As the imperative to produce, report and disseminate research grows across the world, there is a dire need for academic writers to be better prepared for meeting the demands of the scholarly discourse community as to quality academic writing.

\section{Conclusion}

The study concludes that academic writing has gained considerable importance in the universities of non-native countries, particularly those located in urban areas. However, there is a need for greater focus on developing the academic writing skills of university students, especially in rural settings, so that they are able to report their research and convey their findings effectively within the scholarly community. A wide range of communicative options must be adopted by the writers in order to establish claims while at the same time preempting any refutations that the readers may be inclined to present in response to the information presented. This also connects to the idea that the reader plays an active role in how the writer uses said communicative options. Further, it is also important to ascertain specific recurring patterns of communicative discourse. for writers to establish more credibility for their claims. These claims must be established in such a way that the personal accountability of the writer is distanced from the speculations that are presented. To understand the features and recurrences of the communicative options used in academic writing, certain approaches must be adopted as the functions for these options are subjective in nature and thus may overlap given variance in interpretations. This is also a notable problem when examining specific features of academic publications as they may adopt varying approaches to the categorization of content.

\section{References}

Bazerman, C. (1988). Shaping written knowledge: The genre and activity of the experimental article in science (vol. 356). University of Wisconsin Press Madison.

Biber, D., Conrad, S., \& Cortes, V. (2003). Lexical bundles in speech and writing: An initial taxonomy.

Brett, P. (1994). A genre analysis of the results section of sociology articles. English for Specific Purposes, 13(1), 47-59. https://doi.org/10.1016/0889-4906(94)90024-8

Chen, Y.-H., \& Baker, P. (2010). Lexical bundles in L1 and L2 academic writing. Language Learning \& Technology, 2.

Hyland, K. (2000). It might be suggested that. Australian Review of Applied Linguistics (Supplement Series), 16(1), 83-97. https://doi.org/10.1075/aralss.16.06hyl

Hyland, K. (2005). Stance and engagement: A model of interaction in academic discourse. Discourse Studies, 7(2), 173-192. https://doi.org/10.1177/1461445605050365

Hyland, K. (2008). As can be seen: Lexical bundles and disciplinary variation. English for Specific Purposes, 27(1), 4-21. https://doi.org/10.1016/j.esp.2007.06.001

Kaplan, R. B. (1972). The Anatomy of Rhetoric: Prolegomena to a Functional Theory of Rhetoric (vol. 8). Essays for Teachers, Language and the Teacher: A Series in Applied Linguistics.

Labaree, R. V. (2009). Research Guides: Organizing Your Social Sciences Research Paper: Qualitative Methods.

MacDonald, S. (1994). Professional academic writing in the humanities and social sciences. SIU Press.

Mohan, B. A., \& Lo, W. A.-Y. (1985). Academic Writing and Chinese Students: Transfer and Developmental Factors. TESOL Quarterly, 19(3), 515-534. https://doi.org/10.2307/3586276

Nasseri, D., \& Nematollahi, B. (2014). A contrastive genre analysis of abstract of master of arts (ma) Theses in applied linguistics written by native and non-native speakers Of English with respects to moves and move markers. Indian J. Sci. Res., 7(1), 1353-1366. 
Swales, J. (1990). Genre analysis: English in academic and research settings. Cambridge University Press.

\section{Copyrights}

Copyright for this article is retained by the author, with first publication rights granted to the journal.

This is an open-access article distributed under the terms and conditions of the Creative Commons Attribution license (http://creativecommons.org/licenses/by/4.0/). 